\title{
Elementos para uma discussão sobre reforma agrária
}

RELATOR: HELIO ZYLBERSTAJN

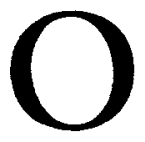

PNBE - PENSAMENTO Nacional das Bases Empresariais e o IEA - Instituto de Estudos Avançados da USP, interessados em contribuir para uma discussão informada sobre a questão agrária, convidaram alguns especialistas para participar de um workshop. O objetivo do evento era criar uma agenda abrangente para a questão.

\section{Metodologia}

Para tratar de um tema tão complexo e com tantos interesses envolvidos, foi utilizada uma metodologia apropriada, que permitiu que prevalecesse a objetividade na discussão. O evento foi conduzido pelo professor James Wright (FEA-USP), que utilizou uma técnica de dinâmica de grupo (Análise e Estruturação de Modelos ISM). Ao final de oito horas de trabalho, o grupo chegou a uma árvore de elementos (objetivos e meios), que, na sua visão, são necessários para equacionar a questão agrária no Brasil.

\section{Processo}

O evento foi realizado na Faculdade de Economia da USP, no dia 17 de maio de 1997. Dele participaram Bernardo Mançano Fernandes (Unesp), Erly Cardoso Teixeira (Universidade Federal de Viçosa), Gilson Alceu Bittencourt (Deser), José Ely da Veiga (USP), Marcos Jank (USP), Pedro Camargo Neto (PNBE) e Zander Navarro (UFRGS). Dadas as limitações de tempo, as dificuldades de reunir um grupo tão expressivo de intelectuais e a enorme complexidade do tema, o resultado obtido pode ser qualificado como bastante expressivo. Os participantes mergulharam em uma discussão rica, intensa e, principalmente, muito objetiva e produtiva. Ao final do dia, estavam reunidos os elementos essenciais da questão agrária, em uma árvore de objetivos e meios, conforme o entendimento do grupo.

\section{Resultado}

O grupo de especialistas listou os elementos que devem ser contemplados para a solução da questão agrária, formando a seguinte árvore de objetivos e meios: 


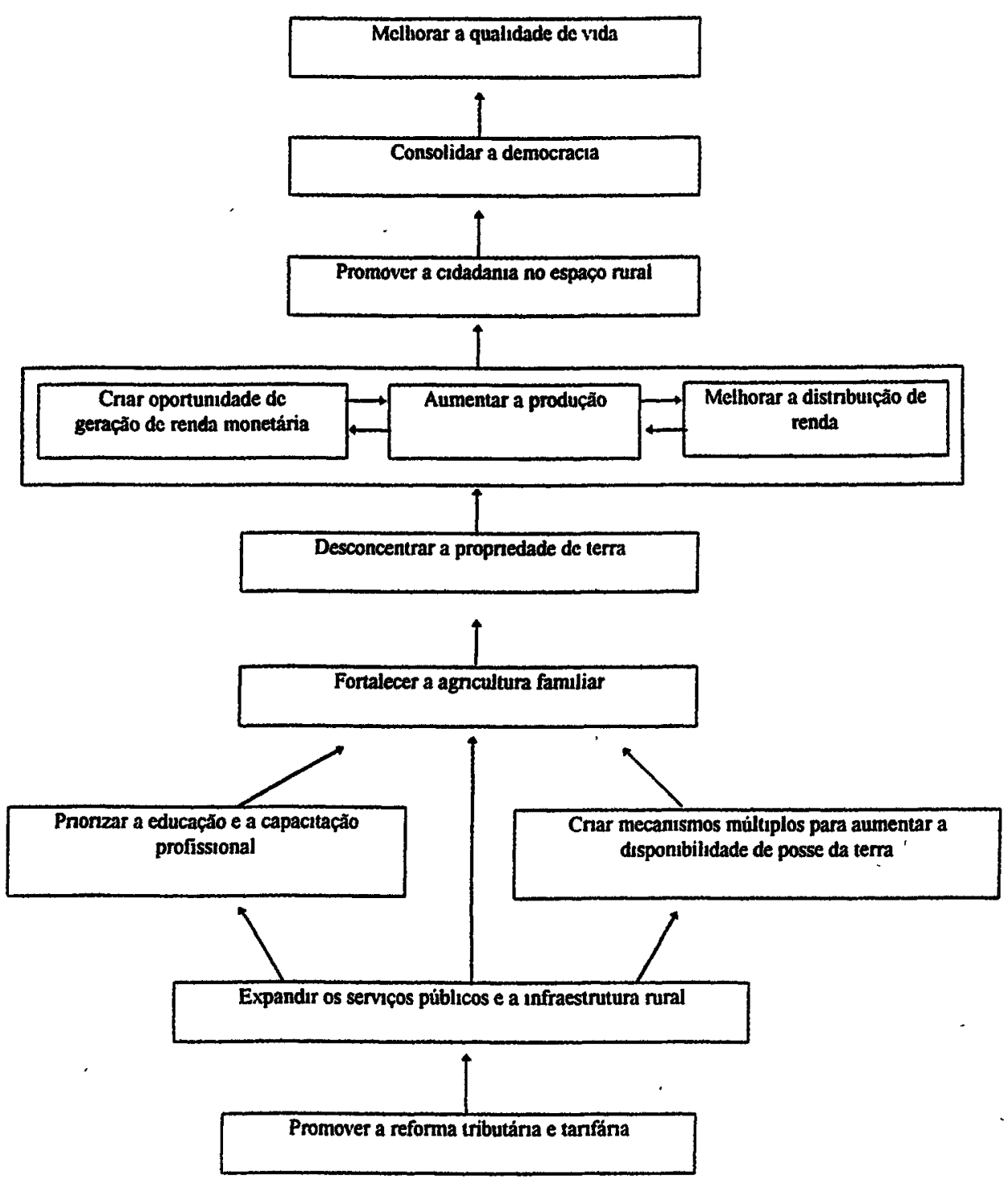


Ao analisar o resultado da discussão do dia, os participantes concordaram que a lista de elementos permite a visão abrangente desejada pelos organizadores e constitui uma contribuição importante para a discussão mais qualificada da questão agrária. Concordaram também que o desenvolvimento de uma agricultura patronal moderna não é incompatível com o desenvolvimento da agricultura familiar.

\section{Avaliação}

O IEA e o PNBE consideram que o trabalho realizado pelos especialistas mostra claramente que a discussão da questão agrária tem se pautado por apenas alguns dos seus múltiplos aspectos $\mathrm{e}$, em geral, sem considerar as prioridades dos mesmos. A árvore de elementos sugere que seria muito importante passar a discuti-la de forma mais completa e ordenada. O trabalho não é conclusivo e não representa um consenso, mas constitui uma lista de pontos para estruturar a discussão. Nesse sentido, os organizadores o consideram uma contribuição importante para o encaminhamento da questão agrária.

Hélio Zylberstajn é professor da Faculdade de Economia e Administração da USP. 